\title{
Investigation on Heat Transfer Enhancement in Microchannel Using $\mathrm{Al}_{2} \mathrm{O}_{3}$ /Water Nanofluids
}

\author{
Arunkumar Munimathan $\mathbb{D D}^{1}{ }^{1}$ T. Sathish $\left(\mathbb{D},{ }^{2}\right.$ V. Mohanavel $\mathbb{D}^{3},{ }^{3}$ Alagar Karthick $\left(\mathbb{D},{ }^{4}\right.$ \\ R. Madavan, ${ }^{5}$ Ram Subbiah, ${ }^{6}$ Chandran Masi, ${ }^{7}$ and S. Rajkumar ${ }^{8}{ }^{8}$ \\ ${ }^{1}$ Department of Agriculture Engineering, Sri Shakthi Institute of Engineering and Technology, Coimbatore, \\ 641062 Tamilnadu, India \\ ${ }^{2}$ Department of Mechanical Engineering, Saveetha School of Engineering, SIMATS, Chennai, 602105 Tamil Nadu, India \\ ${ }^{3}$ Centre for Materials Engineering and Regenerative Medicine, Bharath Institute of Higher Education and Research, Chennai, \\ 600073 Tamilnadu, India \\ ${ }^{4}$ Department of Electrical and Electronics Engineering, KPR Institute of Engineering and Technology, Coimbatore, \\ 641407 Tamilnadu, India \\ ${ }^{5}$ Department of Electrical and Electronics Engineering, PSR Engineering College, Sivakasi, Tamilnadu, India \\ ${ }^{6}$ Department of Mechanical Engineering, Gokaraju Rangaraju Institute of Engineering and Technology, 500090, Nizampet, \\ Hyderabad, India \\ ${ }^{7}$ Department of Biotechnology, College of Biological and Chemical Engineering, Addis Ababa Science and Technology University, \\ Addis Ababa, Ethiopia \\ ${ }^{8}$ Department of Mechanical Engineering, Faculty of Manufacturing, Institute of Technology, Hawassa University, Ethiopia
}

Correspondence should be addressed to Arunkumar Munimathan; mrarunapdpi@gmail.com

and S. Rajkumar; rajkumar@hu.edu.et

Received 9 April 2021; Revised 25 July 2021; Accepted 16 August 2021; Published 14 September 2021

Academic Editor: Ahmad Umar

Copyright (c) 2021 Arunkumar Munimathan et al. This is an open access article distributed under the Creative Commons Attribution License, which permits unrestricted use, distribution, and reproduction in any medium, provided the original work is properly cited.

\begin{abstract}
Nowadays, reducing heat generation in electronic devices while using microchannel cooling is used to solve this problem. Because the trend is globally marching toward the compact size, the component's dimensions get smaller, but the warmth involved within the component increases. Studies of heat transfer rate are conducted to determine the effect of a fully heated microchannel conductor's heat transfer performance. Experiments are performed using nanofluid $\mathrm{Al}_{2} \mathrm{O}_{3} /$ water through a concentration percentage of $0.1 \%$ and $0.25 \%$ and deionized water through a microchannel conductor with 25 rectangular microchannel numbers with a dimension of $(0.42 \times 0.42 \times 100) \mathrm{mm}^{3}$. This present work deals with the effect of nanofluids and their concentration percentages. Finally, it concluded that better heat transfer performance was seen in nanofluids compared to deionized water. The reason is the high viscosity of nanofluid $\mathrm{Al}_{2} \mathrm{O}_{3}$ /water due to these nanoparticles is deposited on the wall surface of the microchannel and outcomes trendy improvement in the heat transfer. Finally, a high concentration percentage of nanofluids revealed a practical improvement in the transfer of microchannel. As a result, $0.25 \%$ of the concentration percentage achieved a satisfactory result compared to the remaining fluids and almost $32.5 \%$ and $26 \%$ of thermal resistance decrease.
\end{abstract}

\section{Introduction}

The microchannel is one of the significant materials to reduce the channel's size to the small resolve reason rise in heat transfer rate. The microchannel is an essential material used to reduce the channel's size to a small resolution to increase heat transfer [1]. Made of silicon-based microchannels, the Pyrex cover plates are bonded to the anode and maintain constant heat flux. The maximum of 2100 is the Reynolds number, the heat transfer rate of $760 \mathrm{~W} / \mathrm{cm}^{2}$, and the 2 bar is the pressure drop [2]. It was found that the microchannel conductor will be prepared to dissipate over 
the water inlet temperature with a maximum substratum temperature increase of $7^{\circ} \mathrm{C}$. Flow maldistribution depends on several factors like device geometry (cross-section and inlet and outlet shapes, sizes, engineering tolerances, or inadequacies) and functioning circumstances (some of the variation of fluid flow rate, viscosity, and thermophysical changes) [3]. A flow guide plate has been added to scale back the flow maldistribution and extend the heat mass transfer. It had been found that flow maldistribution and average temperature decreased while increasing the number of fluid guides [4]. Extreme maldistribution is observed at the header with circular header configuration, while flow through all channels was almost homogenous with a tapered header configuration [5]. When comparing circular cross-section and tapered cross-section, the sharp cross-section header displayed less fluctuation than the circular cross-section header indicating additional constant channel flow [6]. Within a simulation study, eight strategies were considered to know uniform flow distribution, and it had been identified. The only design to know was the direct enlargement of the distribution header [7]. Higher Reynolds numbers were advantageous but with a more significant pressure drop for the heat sink. While observing the temperature distribution within the heat sink, the numerical predictions and experimental data matched well [8,9]. Numerically and experimentally, water-cooled microchannel heat sink performance and found a new correlation incorporating the effects of both channel size and coolant mass velocity to improve pressure drop prediction [10]. The temperature-dependent thermophysical property method was used to investigate the effect of microchannel measurements and, consequently, properties like fluid flow and physical thermo [11]. The coefficient of heat transfer and the microchannel conductor's thermal resistance was compared with the experimental results and located to have good agreement [12].

In metallic copper channels, two types are single and multichannel and have better heat transfer performance and pressure drop by using R134a refrigerant and water. Theoretical results of R134a refrigerant and water were compared to experimental results [12]. Heat transfer characteristics in rectangular microchannels to explore the validity of theoretical correlations. The experiment was performed with water and FC770. The following factors are essential for enhancing nanofluid performance: size, material, volume, temperature, and dispersant [4]. The heat transfer performance is affected by the base fluid, material of nanoparticles, volumes, temperature, size of nanoparticles, and flow properties [13]. The total loss in pressure was calculated for the flow rate and rate of flow and ratio of sectional area to the valve and $n$ number of channels. In the heat exchanger, the flow rate was enhanced based on total pressure loss [14]. The enhancement in heat transfer while using copper/water nanofluid was carried out with the help of a fin, which has 100 and 57-nanometre dimensions. It was observed that the heat transfer coefficient was significantly increased due to existing nanoparticles. Heat transfer enhancement is gradually increasing when thermal conductivity and thermal resistance are increasing. One crucial factor is that there is no extra pressure drop when using nanofluids because of their size and volume $[15,16]$. Nanofluids through metal nanoparticles exhibited better cooling performance than nanofluids with nonmetallic particles owing to the developed thermal conductivity of metal nanofluids. When the volume concentration and Reynolds number increased, the nanofluids would increase the heat transfer [17]. It had also been observed that there was no noticeable increase within the friction factor by adding nanoparticles into the clean water. The best heat transfer improvement remained aimed at $\mathrm{CuO} /$ water nanofluid for given values [18]. The type of base fluids mainly influenced the heat transfer augmentation of nanofluids, the ratio of ethylene glycol: water mixture, the material of nanoparticles, volume concentration, temperature, nanoparticle size, and flow characteristics [19]. The friction, pumping power got considerably increased with the utilization of nanofluid. The ratio of Brownian movement and thermophysical effects had relatively significant effects [20]. The rationale was that the warmth transfer between fluid and channel walls intensified due to interruption of flow by the thermal gesture of nanoparticles. Hydrodynamic and warmth transfer behavior of nanofluid was predicted well while considering the slip length with nanofluid thermophysical properties [21, 22]. The friction factor decreased with the Reynolds number, thermal resistance decreased with pumping power, and input heat in a rectangular microchannel heat sink made of copper using water as a working fluid [23]. A conventional analysis approach can predict heat transfer behavior in microchannels since the numerical predictions showed good agreement with the experimental data. A single rectangular microchannel heat sink is with $\mathrm{Al} 2 \mathrm{O} 3$ as nanoparticle and base fluid such as water and ethylene glycol with various volume concentrations $0.6 \%, 1.2 \%$, and $1.8 \%$ [24]. Experiments were carried out to investigate the effect of volume concentrations of the nanoparticles on convective heat transfer and fluid flow in microchannels. Appreciable enhancement of the convective heat transfer coefficient was found with nanofluids, with the base fluid of water and ethylene glycol without significant friction loss [25].

A single rectangular microchannel heat sink is with $\mathrm{CuO} /$ water nanofluid with various volume concentrations such as $4.5 \%, 1.03 \%$, and $0.24 \%$ under both laminar and turbulent conditions. For nanofluid, there was a slight heat transfer enhancement with low particle volume concentration. For a given Reynolds number, nanofluid overall energetic performance, defined by heat transferred/pumping power ratio, remained lower than water [26]. The decrease in the ratio was due to the augmentation of the particle volume concentration. The heat transfer performance and pressure drop of nanofluids in a microchannel heat sink are with $\mathrm{TiO} 2 /$ water nanofluid of different volumetric concentration ratios of $0.25 \%, 0.5 \%, 1.0 \%, 1.5 \%$, and $2.0 \%$ to analyze the upper limitation of the particle volume concentration for heat transfer performance [27]. It was identified that by using nanofluid up to $2.0 \%$, the heat transfer increased, and the heat transfer decreased after the volumetric ratio of $2.0 \%$. The thermal resistance of nanofluid decreased by adding nanoparticles with an average diameter smaller than $25 \mathrm{~nm}$ into the base fluid [28]. In a single microchannel with 
two types of nanofluid such as $\mathrm{Al} 2 \mathrm{O} 3 /$ water and $\mathrm{SiO} 2 /$ water with a volumetric concentration of $0.005 \%, 0.01 \%$, and $0.02 \%$ and found $\mathrm{Al} 2 \mathrm{O} 3 /$ water had a significantly high heat transfer coefficient. It was seen that $\mathrm{Al} 2 \mathrm{O} 3 /$ water nanofluid had more extraordinary ability in disrupting the thermal boundary layer profiles and lead to a higher percentage reduction in thickness of boundary layers. Al2O3/water showed a higher heat transfer coefficient than the $\mathrm{SiO} 2 /$ water and the base fluid $[23,29,30]$. The various performance values of microchannels with various nanofluids are listed in Table 1. According to Table 1, there are so many moderate values in heat transfer rate, thermal resistance, and pressure drop based on nanofluid type.

According to the literature studies, it was found that there is limited researchers carried out with the combined effect of nanofluid with microchannel; also, no results were found for various inputs. Hence, the heat transfer rate in the microchannel, the consequence of $\mathrm{Al}_{2} \mathrm{O}_{3}$ with water nanofluids is investigated with various power outputs and because of optimum cost this $\mathrm{Al}_{2} \mathrm{O}_{3}$ /water will frequently act as a coolant for small photovoltaic applications. The scanning electron microscopy is carried out to analyze the performance enhancement of the microchannel conductor performance under thoroughly heated conditions has been experimentally investigated.

\section{Preparation of Nanofluid}

Nanofluids are prepared using $\mathrm{Al}_{2} \mathrm{O}_{3}$ (alumina) particle blended with water through a magnetic stirrer at a rate of $1000 \mathrm{rpm}$, as shown in Figure 1. Mixed $\mathrm{Al}_{2} \mathrm{O}_{3}$ particles and distilled water were also processed at $60^{\circ} \mathrm{C}$ in the ultrasonic bath for 60 minutes, as shown in Figure 2 with $490 \mathrm{~kW}$ and $18 \mathrm{kHz}$ frequency. Two concentration percentages of $0.1 \%$ and $0.25 \%$ have been used in this nanofluid preparation. The JSM IT-800 SEM (scanning electronics microscope operating at $5 \mathrm{kV}$ ) image is pure nanoparticles, as shown in Figure 3. The required alumina was purchased from nanoshell, India, which is used to prepare a nanofluid. It was found that $40 \mathrm{~nm}$ is the average particle size by using Sherrer's equation.

$$
d=\frac{0.9 \lambda}{\beta \cos \theta} .
$$

Pak and Cho's equation (2) is used to calculate the nanofluids density,

$$
\rho n f . \rho n f=\varphi \rho s+(1-\varphi) \rho
$$

The Maxwell equation (3) is used to find out the thermal conductivity,

$$
\frac{K n f}{K}=\frac{K s+2 K+2 \varnothing(K s-K)}{K s+2 K-\varnothing(K s-K)} .
$$

Nanofluid's specific heat is calculated using Xuan and Roetzel's equation

$$
(\rho c p) n f=(1-\varphi)(\rho c p)+\varphi(\rho c p) s
$$

Viscosity plays a main role in fluids. This viscosity is calculated by using Einstein equation

$$
\mu n f=\mu(1+2.5 \varphi) .
$$

The $\mathrm{pH}$ upsides of the prearranged nanofluids are estimated by using digital $\mathrm{pH}-14 \mathrm{~L}$ and discovered to associate with 5 , which is a long way from the isoelectric point of 9 for alumina nanoparticles. This guarantees that the nanoparticles are all around scattered, and the nanofluid is steady a direct result of huge loathsome powers among the nanoparticles when $\mathrm{pH}$ is a long way from isoelectric point. At isoelectric point, the loathsome powers between particles are excessively feeble, permitting the particles to move toward one another and in the long run agglomerate, influencing the solidness of the suspensions. Moreover, Zeta potential has been estimated using Japanese nanomolecule analyser and discovered to be $+43 \mathrm{mV}$ to $+47 \mathrm{mV}$, which is demonstrative of acceptable strength of the nanofluid. A $\mathrm{pH}$ worth of 3.7 to 5.2 will keep the nanofluids stable for a long time.

The properties of working fluid are found as illustrated in Table 2.

\section{Experimental Setup}

The microchannel cooling system utilized within the experimental study is displayed in Figure 4. Set up comprises test section, pump, liquid reservoir, pressure transducer, computerized system to store the data, and a collecting tank. The channel size is identical to that of flow distribution studies. An oblong header with a width of $1 \mathrm{~cm}$, depth of $0.5 \mathrm{~cm}$, and length of $19.6 \mathrm{~cm}$ is used, as shown in Figure 5. The test section of the microchannels is shown in the schematic view.

To look at the fluid flow within the microchannels, the examination device is fixed in the roofed clear board. The lowest layer that is the examination portion was formed to improve the heater. Therefore, the test section has been well protected from ameliorating the heat energy loss. The microchannel conductor's surface heat flow and the inlet and outlet heat flow for a working fluid are calculated using temperature sensors. The thermocouples are fixed at the test section at various places and a total of 10 thermocouples. Eight numbers are in aluminum blocks with an equal distance of $50 \mathrm{~mm}$ at the edges of both sides in the bottom layer of the microchannels conductor to reside the surface temperatures monitor the heat flow. Experiments are performed in a mircochannel using three types of fluids: two $\mathrm{Al}_{2} \mathrm{O}_{3}$ /water nanofluids with concentration percentages of $0.1 \%, 0.25 \%$, and deionized water are conducted to measure the microchannel conductor's pressure drop and heat transfer performance. 
TABLE 1: Performance of microchannel used with various nanofluid additives.

\begin{tabular}{|c|c|c|c|c|}
\hline Type of nanofluid used & $\begin{array}{l}\text { Heat transfer rate } \\
\qquad\left(\mathrm{W} / \mathrm{m}^{2} \mathrm{~K}\right)\end{array}$ & $\begin{array}{c}\text { Thermal resistance } \\
(\mathrm{K} / \mathrm{W})\end{array}$ & $\begin{array}{l}\text { Pressure drop } \\
\qquad\left(\mathrm{N} / \mathrm{m}^{2}\right)\end{array}$ & Reference \\
\hline SiO2-based dilute nanofluids & 153 & - & 0.0020 & {$[5]$} \\
\hline Ethylene glycol: water nanofluids & 165 & 1.1 & 0.0022 & {$[23]$} \\
\hline CU-water nanofluid & 144 & 1.0 & 0.0024 & {$[3]$} \\
\hline Water-Fe3O4/CNT hybrid nanofluid & 160 & - & 0.0025 & [18] \\
\hline Oil/MWCNT nanofluid & 140 & 0.85 & - & {$[20]$} \\
\hline Water/CuO nanofluid and L-shaped porous ribs & 150 & 0.7 & 0.0028 & {$[16]$} \\
\hline Al2O3-water nanofluids & 165 & 0.6 & 0.0030 & {$[14]$} \\
\hline Hybrid nanofluid & 157 & - & 0.0031 & {$[2]$} \\
\hline Graphene nanoplatelets-silver/water nanofluids & 168 & 0.83 & 0.0023 & {$[27]$} \\
\hline FMWCNT nanofluids & 146 & 0.81 & - & {$[28]$} \\
\hline
\end{tabular}

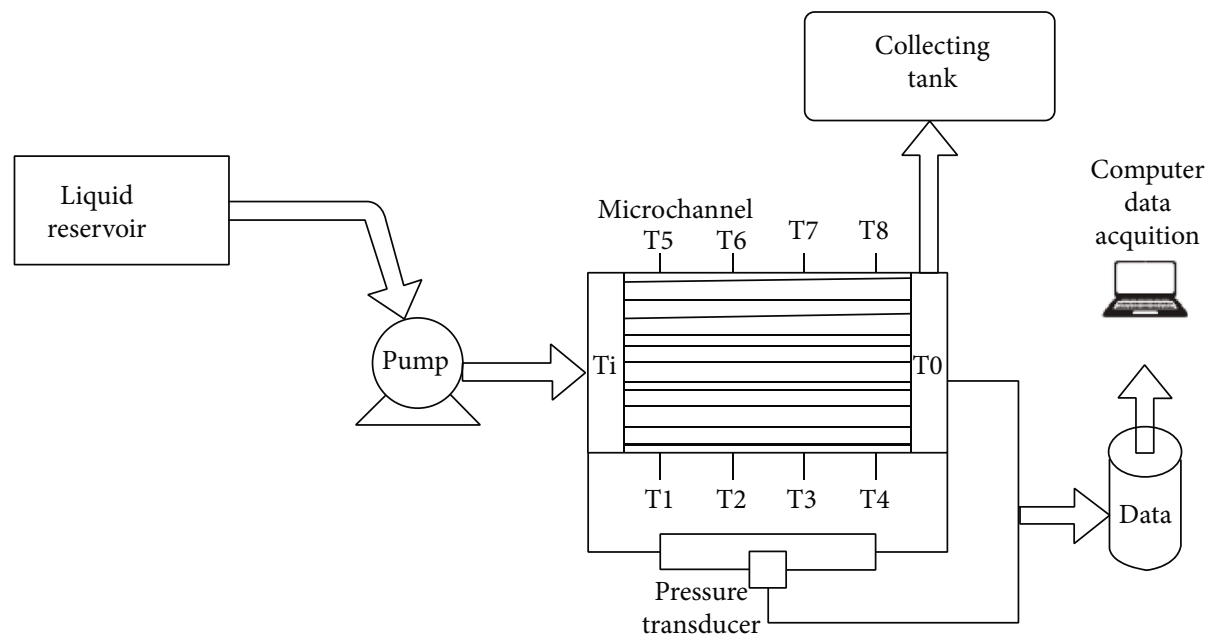

Figure 1: Preparation of nanofluid using a magnetic stirrer.

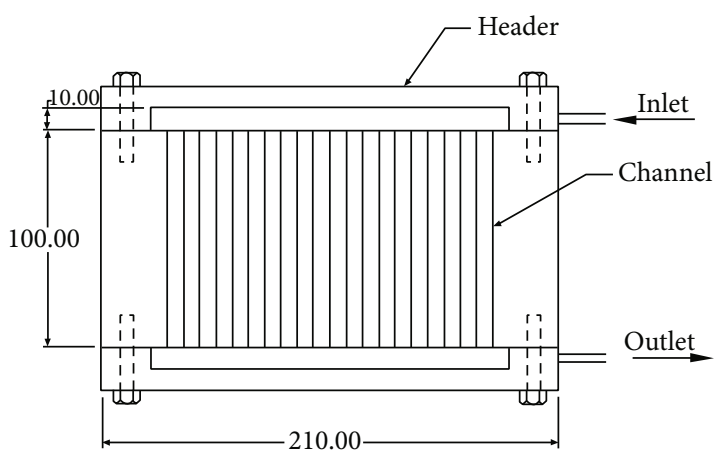

All dimensions are in $\mathrm{mm}$.

FIgURE 2: Preparation of nanofluid using an ultrasonic bath.

\section{Experimental Procedure}

The test was initiated by a heater connected to the bottom section of the microchannel. The test section consists of the outlet header and the collection container used for fluid flow and storage purposes. Until the beginning of the exper-

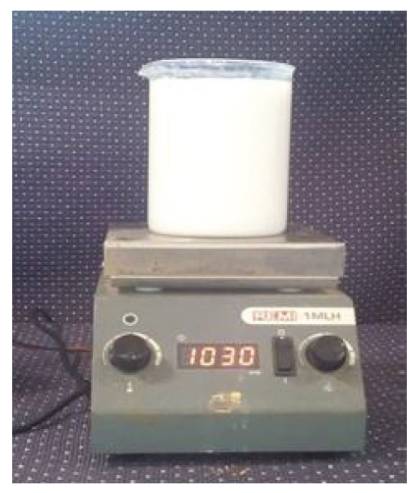

FIgUre 3: SEM image of $\mathrm{Al}_{2} \mathrm{O}_{3}$ nanoparticle.

iment, the temperature sensors are set to maintain the water bath at a constant temperature. Pressure transducers can calculate the fluid flow state of the inlet and outlet pressure and the difference. In this work, fluid and surface temperatures were monitored every 5 seconds through a computerized data acquisition system. Initially, microchannels inspect the leakage of the test segment by applying water 
TABLE 2: Properties of working fluids.

\begin{tabular}{|c|c|c|c|}
\hline Properties & Deionized water & $\mathrm{Al}_{2} \mathrm{O}_{3} /$ water $(0.1 \%)$ & $\mathrm{Al}_{2} \mathrm{O}_{3} /$ water $(0.25 \%)$ \\
\hline Thermal conductivity (K) & $0.485 \mathrm{~W} / \mathrm{mK}$ & $0.635 \mathrm{~W} / \mathrm{mK}$ & $0.654 \mathrm{~W} / \mathrm{mK}$ \\
\hline Density $(\rho)$ & $1015 \mathrm{~kg} / \mathrm{m}^{3}$ & $1030 \mathrm{~kg} / \mathrm{m}^{3}$ & $1040 \mathrm{~kg} / \mathrm{m}^{3}$ \\
\hline Specific heat $\left(C_{p}\right)$ & $3800 \mathrm{~J} / \mathrm{kgK}$ & $3720 \mathrm{~J} / \mathrm{kgK}$ & $3712 \mathrm{~J} / \mathrm{kgK}$ \\
\hline Viscosity $(\mu)$ & $0.00145 \mathrm{Ns} / \mathrm{m}^{2}$ & $0.0010 \mathrm{Ns} / \mathrm{m}^{2}$ & $0.00120 \mathrm{Ns} / \mathrm{m}^{2}$ \\
\hline
\end{tabular}

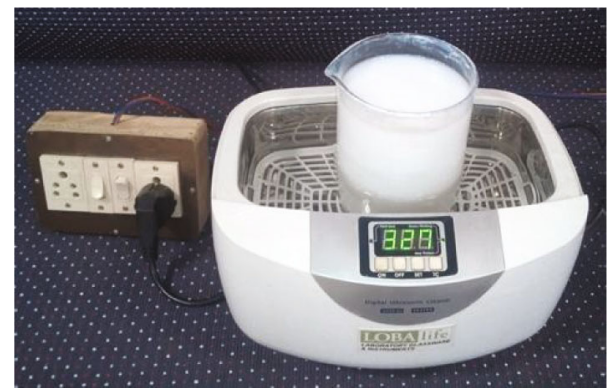

Figure 4: Conceptual design.

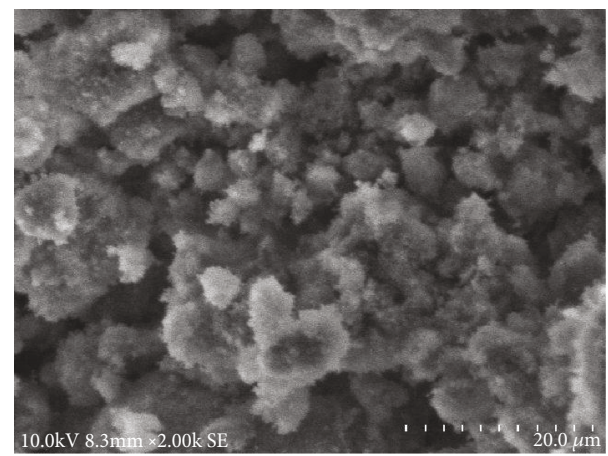

FIgURe 5: Part of microchannel check-schematic view.

immersion and pressurized air. After that, the fluid movement with or without a channel ensures the passage of potash permanganate-a water solution. Testing was performed for various heat input conditions and fluid flow rates. The system has come to a steady-state. It has taken up to 1 hour. In this research work, all data on the measured pressure and temperature of the microchannel were stable, and the fluid temperature of $30^{\circ} \mathrm{C}$ was maintained throughout the entire experiment. To ensure the repeatability test, the investigational analysis was replicated, aimed at several occasions taking place various beings.

\section{Uncertainty in the Experiments}

The experiments are conducted with the following uncertainty limits as shown in the table, calibrated using the visual inspection machine system in Table 3. It was found that $\pm 1.71 \%$ of uncertainty was obtained for the microchannel with the dimension of $0.42 \mathrm{~mm}$ width and depth, $100 \mathrm{~mm}$ length, and $10 \mathrm{~mm}$ of width, $5 \mathrm{~mm}$ of depth, and $196 \mathrm{~mm}$ of length. These uncertainty values depend on the errors, which all are in the measured quantities. Based on the mea-
TABle 3: Parameters uncertainty.

\begin{tabular}{lc}
\hline Parameters & Uncertainty limits \\
\hline Dimensions (microchannel size) & $\pm 1.71 \%$ \\
Thermal resistance & $\pm 0.2 \%$ \\
Reynolds number & $\pm 3.5 \%$ \\
Heat transfer coefficient & $\pm 2.36 \%$ \\
Temperatures (inlet and outlet) & $\pm 0.2{ }^{\circ} \mathrm{C}$ \\
\hline
\end{tabular}

sured quantity values, it was observed that $\pm 0.2 \%$ is the error value for thermal resistance and $\pm 3.5 \%$ for Reynolds number. The same error and uncertainty values are calculated for both inlet and outlet temperatures and base temperature also, and it was observed that $\pm 0.2 \%$ and $\pm 2.36 \%$.

\section{Result and Discussion}

In this research work, the microchannel conductor is a device used to determine the performance of a heat transfer rate using nanofluid $\mathrm{Al}_{2} \mathrm{O}_{3}$ /water at a concentration of $0.25 \%, 0.1 \%$, and deionized water with various heat inputs such as $6 \mathrm{~W}, 12 \mathrm{~W}$, and $15 \mathrm{~W}$.

Analysis carried out plotting the graphs with a heat transfer coefficient, a dimensionless coefficient, thermal resistance with pressure drop are contrasted with variable Reynolds number to compare the results of deionized water with $\mathrm{Al}_{2} \mathrm{O}_{3}$ /water nanofluids.

6.1. Influence Impact of Heat Transfer Rate. Present work and the heat transfer rate in the microchannel conductor by applying nanofluids were shown in Figures 6-8. $\mathrm{Al}_{2} \mathrm{O}_{3}$ /water nanofluids are $0.1 \%, 0.25 \%$, compared to the deionized water heat transfer coefficient versus the different conditions of the Reynolds number. From the results obtained, the maximum and minimum heat transfer coefficients are in $\mathrm{Al}_{2} \mathrm{O}_{3}$ /water nanofluids $(0.25 \%)$ and deionized water for all conditions of Reynolds numbers. Improved nanofluids are discussed with water due to significant thermal conductivity and heat capacity, and thermal dispersion in nanoparticles. As a result, high thermal power in nanofluid contrasts with deionized water increases heat transfer rate. Contrasted to deionized water, significantly improved heat transfer is $37 \%$ while also nanofluid $\mathrm{Al}_{2} \mathrm{O}_{3}$ /water at a concentration percentage of $0.25 \%$ by volume at the considered absolute best Reynolds number.

6.2. Influence of Impact in Concentration Percentages in Nanofluids. The impact of the concentration of nanofluid percentages $(0.1 \%, 0.25 \%)$ on the microchannel conductor's 


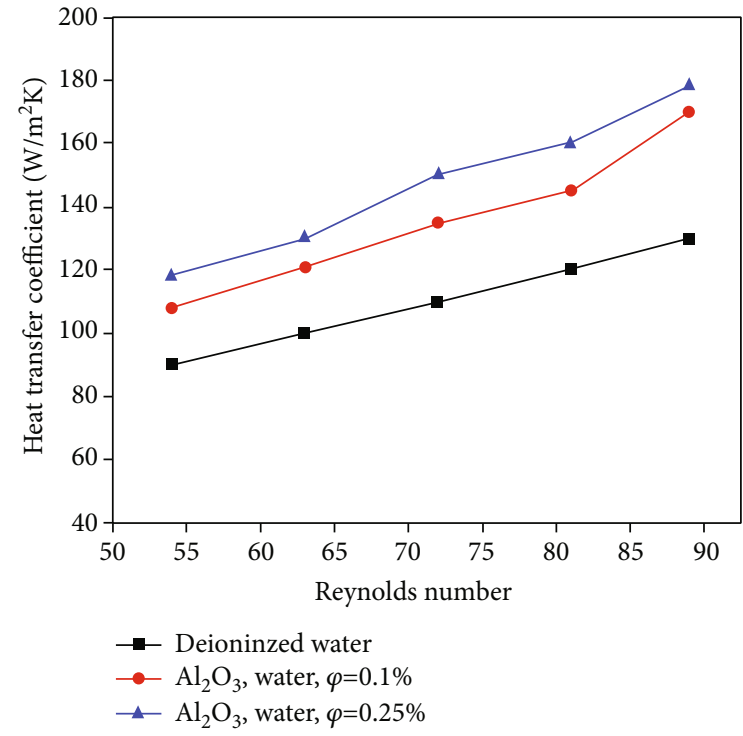

Figure 6: Heat transfer coefficient vs. Reynolds number for heat input of $15 \mathrm{~W}$.

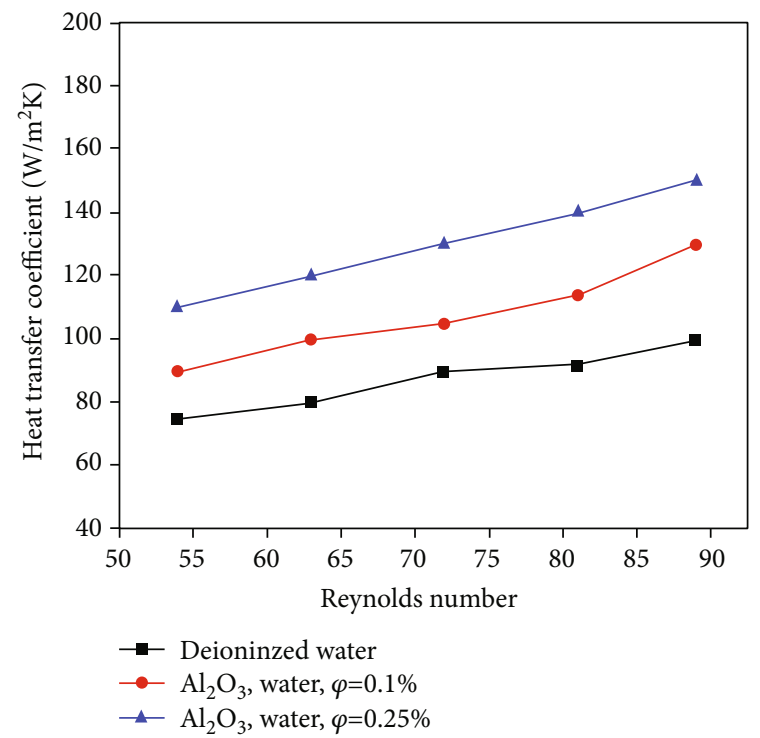

Figure 7: Heat transfer coefficient vs. Reynolds number for heat input of $12 \mathrm{~W}$.

performance was shown by plotting the dimensionless number relative to the Reynolds number as exposed in Figure 9. The mean heat transfer coefficient observed in the $\mathrm{Al}_{2} \mathrm{O}_{3} /$ water nanofluid improved by $0.25 \%$ as per the plotted graph. $\mathrm{Al}_{2} \mathrm{O}_{3}$ /water nanofluid of percentage concentration of 0.25 $\%$ and $0.1 \%$ revealed the $32.8 \%$ and $23.16 \%$ improvement in heat transfer performance. Nanoparticle aggregation and accumulation are observed at high percentage concentrations of nanofluids, and therefore, the amount concentration within this study is limited to $0.25 \%$.

6.3. Influence of Impact in Thermal Resistance in Nanofluids. Figure 10 shows the microchannel conductor thermal resis-

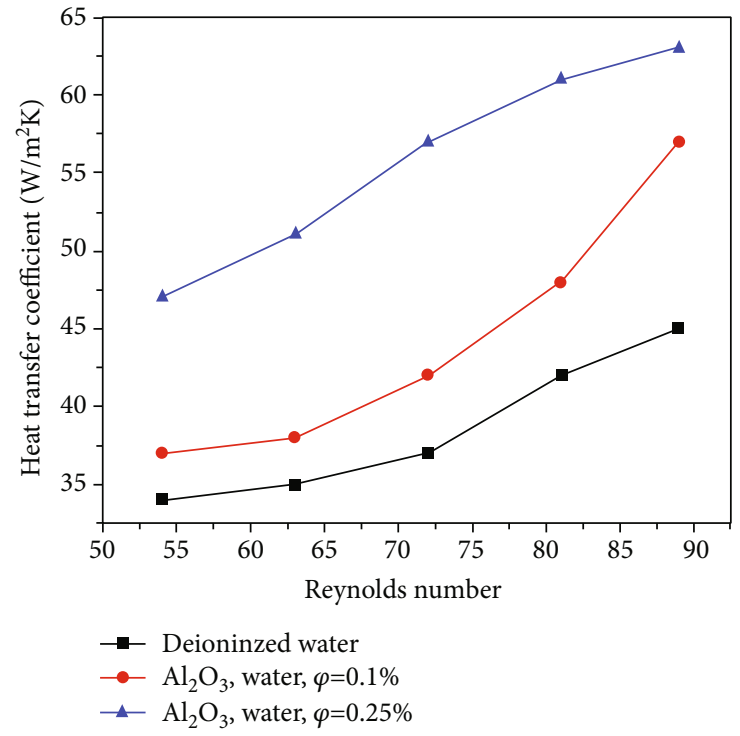

FIgURe 8: Heat transfer coefficient vs. Reynolds number for heat input of $6 \mathrm{~W}$.

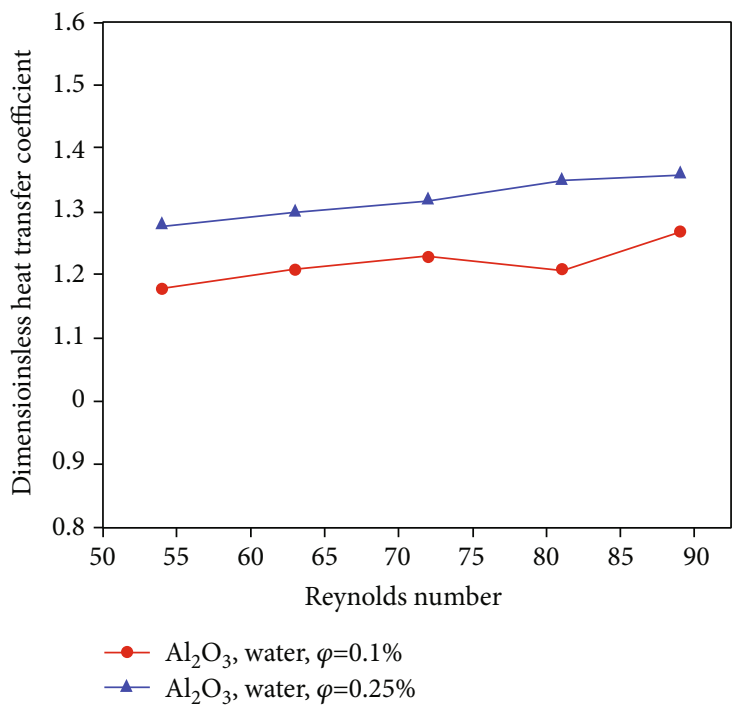

FIGURE 9: Heat transfer coefficient vs. Reynolds heat input number of $15 \mathrm{~W}$.

tance concerning different Reynolds number conditions using $\mathrm{Al}_{2} \mathrm{O}_{3}$ /water nanofluids $(0.1 \%, 0.25 \%)$ and deionized water. Using obtained outcomes, maximum and minimum thermal resistance is deionized water and $\mathrm{Al}_{2} \mathrm{O}_{3}$ /water of $0.25 \%$, respectively. Overall, nanofluids have less thermal resistance than deionized water, which is often representative of lower microchannel wall temperature vital to the heat dissipation of photovoltaic module concentration and electronics devices. Almost $32.5 \%$ and $26 \%$ of thermal resistance decrease in $\mathrm{Al}_{2} \mathrm{O}_{3}$ /water by $0.25 \%$ and $0.1 \%$ compared to deionized water [31-36].

6.4. Influence of Impact in Pressure Drop in Nanofluids. Figure 11 shows the microchannel conductor pressure drop 


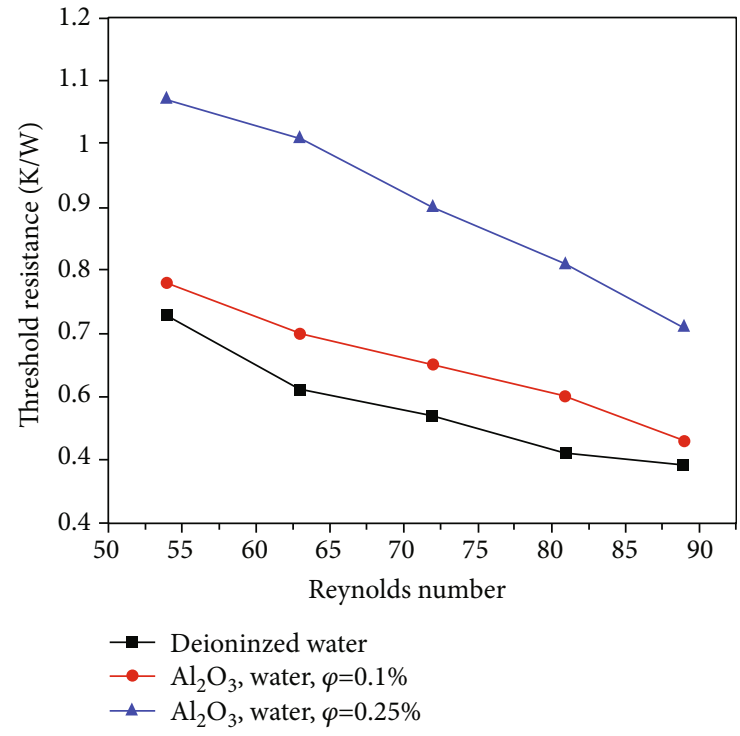

Figure 10: Thermal resistance vs. Reynolds number $15 \mathrm{~W}$ with heat input.

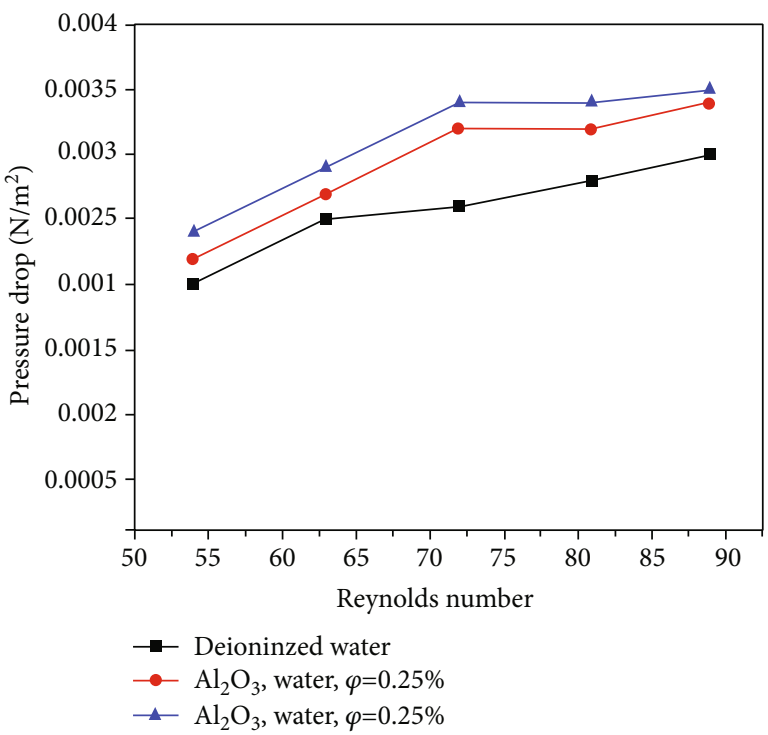

Figure 11: Pressure drop vs. Reynolds number $15 \mathrm{~W}$ with heat input.

concerning different Reynolds number conditions using $\mathrm{Al}_{2} \mathrm{O}_{3}$ /water nanofluids $(0.1 \%, 0.25 \%)$ and deionized water.

When rising the Reynolds number, increases of the pressure drop of fluids were noticed. Overall, minimum pressure drop was observed in deionized water compared to nanofluids. Because nanofluids have high viscosity and the particles of nanofluids are deposited on the channel's surface, it leads to the roughness of the channel surface. Nanofluids have enhanced thermal management applications in electronic devices and many other purposes due to their significant high-pressure drop than deionized water. To achieve this, they require the overall performance of the heat trans- fer. Even so, there is increasing pressure drop in the microchannel at the time of practical applications because of deposition of solid particles [36-40].

\section{Conclusion}

In this research, the experiment carried out in the microchannel conductor using $\mathrm{Al}_{2} \mathrm{O}_{3}$ /water nanofluids at a percentage concentration of $0.25 \%, 0.1 \%$, and deionized water resulted in a recital of heat transfer rate. The findings from the results are

(i) $\mathrm{Al}_{2} \mathrm{O}_{3}$ /water nanofluid of percentage concentration of $0.25 \%$ and $0.1 \%$ revealed the $32.8 \%$ and $23.16 \%$ improvement in heat transfer performance heat transfer augmentation by $\mathrm{Al}_{2} \mathrm{O}_{3}$ /water is higher than deionized water owing to developed effective thermal conductivity. Hence, $\mathrm{Al}_{2} \mathrm{O}_{3}$ /water is a suitable coolant for the thermal management of photovoltaic applications

(ii) Almost $32.5 \%$ and $26 \%$ of thermal resistance decrease in $\mathrm{Al}_{2} \mathrm{O}_{3}$ /water by $0.25 \%$ and $0.1 \%$ compared to deionized water

(iii) Nanofluid concentration percentages are proven to obligate a more significant influence on the microchannel's heat transfer performance. Nanofluid concentration percentages play a vital role in the microchannel recital of heat transfer. High concentration percentages of nanofluids achieved satisfying results due to more substantial thermal dispersion and thermophysical effects

(iv) It was found that this has been considered at the time of microchannel designing for sensitive temperature applications like cooling of photovoltaic cells, cooling of electronic chips, etc.

(v) Consequent nanofluid-induced pressure drop is needed not high that nanofluids are suitable chilling liquids intended for microchannels

\section{Data Availability}

The data used to support the findings of this study are included in the article.

\section{Conflicts of Interest}

The authors declare that there is no conflict of interest regarding the publication of this article.

\section{References}

[1] A. Abdollahi, R. N. Sharma, and A. Vatani, "Fluid flow and heat transfer of liquid-liquid two phase flow in microchannels: a review," International Communications in Heat and Mass Transfer, vol. 84, pp. 66-74, 2017.

[2] H. Arasteh, R. Mashayekhi, D. Toghraie, A. Karimipour, M. Bahiraei, and A. Rahbari, "Optimal arrangements of a heat sink partially filled with multilayered porous media employing 
hybrid nanofluid," Journal of Thermal Analysis and Calorimetry, vol. 137, no. 3, pp. 1045-1058, 2019.

[3] Z. Azizi, A. Alamdari, and M. R. Malayeri, "Convective heat transfer of $\mathrm{Cu}$-water nanofluid in a cylindrical microchannel heat sink," Energy Conversion and Management, vol. 101, pp. 515-524, 2015.

[4] K. Sudalaiyandi, K. Alagar, R. Vignesh Kumar, V. J. Manoj Praveen, and P. Madhu, "Performance and emission characteristics of diesel engine fueled with ternary blends of linseed and rubber seed oil biodiesel," Fuel, vol. 285, p. 119255, 2021.

[5] W. H. Azmi, A. Hamid, N. A. Usri, R. Mamat, and K. V. Sharma, "Heat transfer augmentation of ethylene glycol: water nanofluids and applications - a review," International Communications in Heat and Mass Transfer, vol. 75, pp. 13-23, 2016.

[6] S. Senthilkumar, A. Karthick, R. Madavan et al., "Optimization of transformer oil blended with natural ester oils using Taguchi- based grey relational analysis," Fuel, vol. 288, p. 119629, 2021.

[7] C. Sowmya Dhanalakshmi, P. Madhu, A. Karthick, and R. Vigneshkumar, "Combination of woody and grass type biomass: waste management, influence of process parameters, yield of bio-oil by pyrolysis and its chromatographic characterization," Journal of Scientific and Industrial Research (JSIR), vol. 80, no. 2, pp. 172-180, 2021.

[8] A. R. Prasad, R. Shankar, C. K. Patil, A. Karthick, A. Kumar, and R. Rahim, "Performance enhancement of solar photovoltaic system for roof top garden," Environmental Science and Pollution Research, pp. 1-11, 2021.

[9] A. Rahimi Gheynani, O. Ali Akbari, M. Zarringhalam et al., "Investigating the effect of nanoparticles diameter on turbulent flow and heat transfer properties of non-Newtonian carboxymethyl cellulose/CuO fluid in a microtube," International Journal of Numerical Methods for Heat \& Fluid Flow, vol. 29, no. 5, pp. 1699-1723, 2019.

[10] M. R. Gholami, O. A. Akbari, A. Marzban, D. Toghraie, G. A. S. Shabani, and M. Zarringhalam, "The effect of rib shape on the behavior of laminar flow of oil/MWCNT nanofluid in a rectangular microchannel," Journal of Thermal Analysis and Calorimetry, vol. 134, no. 3, pp. 1611-1628, 2018.

[11] D. Haridas, N. S. Rajput, and A. Srivastava, "Interferometric study of heat transfer characteristics of $\mathrm{Al}_{2} \mathrm{O}_{3}$ and $\mathrm{SiO}_{2}$-based dilute nanofluids under simultaneously developing flow regime in compact channels," International Journal of Heat and Mass Transfer, vol. 88, pp. 713-727, 2015.

[12] A. A. Hussien, M. Z. Abdullah, and M.'d. A. Al-Nimr, "Singlephase heat transfer enhancement in micro/minichannels using nanofluids: theory and applications," Applied Energy, vol. 164, pp. 733-755, 2016.

[13] B. Kim, "An experimental study on fully developed laminar flow and heat transfer in rectangular microchannels," International Journal of Heat and Fluid Flow, vol. 62, pp. 224-232, 2016.

[14] L. S. Maganti and P. Dhar, "Consequences of flow configuration and nanofluid transport on entropy generation in parallel microchannel cooling systems," International Journal of Heat and Mass Transfer, vol. 109, pp. 555-563, 2017.

[15] E. Manay and B. Sahin, "Heat transfer and pressure drop of nanofluids in a microchannel heat sink," Heat Transfer Engineering, vol. 38, no. 5, pp. 510-522, 2017.

[16] E. Manay and B. Sahin, "The effect of microchannel height on performance of nanofluids," International Journal of Heat and Mass Transfer, vol. 95, pp. 307-320, 2016.
[17] R. Mashayekhi, E. Khodabandeh, O. A. Akbari, D. Toghraie, M. Bahiraei, and M. Gholami, "CFD analysis of thermal and hydrodynamic characteristics of hybrid nanofluid in a new designed sinusoidal double-layered microchannel heat sink," Journal of Thermal Analysis and Calorimetry, vol. 134, no. 3, pp. 2305-2315, 2018.

[18] A. Mostafazadeh, D. Toghraie, R. Mashayekhi, and O. A. Akbari, "Effect of radiation on laminar natural convection of nanofluid in a vertical channel with single- and two-phase approaches," Journal of Thermal Analysis and Calorimetry, vol. 138, no. 1, pp. 779-794, 2019.

[19] H. H. Najafabadi and M. K. Moraveji, "CFD investigation of local properties of $\mathrm{Al}_{2} \mathrm{O}_{3}$ /water nanofluid in a converging microchannel under imposed pressure difference," Advanced Powder Technology, vol. 28, no. 3, pp. 763-774, 2017.

[20] M. R. Safaei, G. Ahmadi, M. Goodarzi, M. Safdari Shadloo, H. Goshayeshi, and M. Dahari, "Heat transfer and pressure drop in fully developed turbulent Flows of graphene Nanoplatelets-Silver/Water Nanofluids," Fluids, vol. 1, no. 3, p. 20, 2016.

[21] M. R. Safaei, H. Togun, K. Vafai, S. N. Kazi, and A. Badarudin, "Investigation of heat transfer enhancement in a forwardfacing contracting channel using FMWCNT nanofluids," Numerical Heat Transfer, Part A: Applications, vol. 66, no. 12, pp. 1321-1340, 2014.

[22] A. M. Sahar, M. R. Özdemir, E. M. Fayyadh, J. Wissink, M. M. Mahmoud, and T. G. Karayiannis, "Single phase flow pressure drop and heat transfer in rectangular metallic microchannels," Applied Thermal Engineering, vol. 93, pp. 1324-1336, 2016.

[23] R. Sathyamurthy, A. E. Kabeel, A. Chamkha, A. Karthick, A. Muthu Manokar, and M. G. Sumithra, "Experimental investigation on cooling the photovoltaic panel using hybrid nanofluids," Applied Nanoscience, vol. 11, no. 2, pp. 363-374, 2021.

[24] F. Shafiei and M. R. Talaghat, "Numerical and Galerkin's methods for thermal performance analysis of circular porous fins with various profiles when the surface temperature is higher/lower than the air temperature," Energy Sources, Part A: Recovery, Utilization, and Environmental Effects, pp. 1-19, 2019.

[25] A. Shahsavar, P. T. Sardari, and D. Toghraie, "Free convection heat transfer and entropy generation analysis of water$\mathrm{Fe} 3 \mathrm{O} 4 / \mathrm{CNT}$ hybrid nanofluid in a concentric annulus," International Journal of Numerical Methods for Heat \& Fluid Flow, vol. 29, no. 3, pp. 915-934, 2019.

[26] A. Shahsavar, A. Godini, P. T. Sardari, D. Toghraie, and H. Salehipour, "Impact of variable fluid properties on forced convection of $\mathrm{Fe} 3 \mathrm{O} 4 / \mathrm{CNT} /$ water hybrid nanofluid in a double-pipe mini-channel heat exchanger," Journal of Thermal Analysis and Calorimetry, vol. 137, no. 3, pp. 1031-1043, 2019.

[27] M. Sheikholeslami, Z. Li, and M. Shamlooei, "Nanofluid MHD natural convection through a porous complex shaped cavity considering thermal radiation," Physics Letters A, vol. 382, no. 24 , pp. 1615-1632, 2018.

[28] D. Toghraie, M. Mahmoudi, O. A. Akbari, F. Pourfattah, and $\mathrm{M}$. Heydari, "The effect of using water/CuO nanofluid and Lshaped porous ribs on the performance evaluation criterion of microchannels," Journal of Thermal Analysis and Calorimetry, vol. 135, no. 1, pp. 145-159, 2019.

[29] B. J. Zhu, W. L. Zhao, J. K. Li, Y. X. Guan, and D. D. Li, “Thermophysical properties of $\mathrm{Al}_{2} \mathrm{O}_{3}$-water nanofluids," Materials Science Forum, vol. 688, pp. 266-271, 2011. 
[30] C. Yang, K. Peng, A. Nakayama, and T. Qiu, "Forced convective transport of alumina-water nanofluid in micro-channels subject to constant heat flux," Chemical Engineering Science, vol. 152, pp. 311-322, 2016.

[31] J. Lee and I. Mudawar, "Assessment of the effectiveness of nanofluids for single-phase and two-phase heat transfer in micro-channels," International Journal of Heat and Mass Transfer, vol. 50, no. 3-4, pp. 452-463, 2007.

[32] D. Singh, R. Chaudhary, and A. Karthick, "Review on the progress of building-applied/integrated photovoltaic system," Environmental Science and Pollution Research, vol. 28, no. 35, pp. 47689-47724, 2021.

[33] C. S. Dhanalakshmi, P. Madhu, A. Karthick, M. Mathew, and R. V. Kumar, "A comprehensive MCDM-based approach using TOPSIS and EDAS as an auxiliary tool for pyrolysis material selection and its application," Biomass conversion and biorefinery, 2020.

[34] N. Y. Jayalakshmi, R. Shankar, U. Subramaniam et al., "Novel multi-time scale deep learning algorithm for solar irradiance forecasting," Energies, vol. 14, no. 9, p. 2404, 2021.

[35] V. Rajendran, H. Ramasubbu, K. Alagar, and V. K. Ramalingam, "Performance analysis of domestic solar air heating system using V-shaped baffles-an experimental study," Proceedings of the institution of mechanical engineers, part E: journal of process mechanical engineering, p. 09544089211016256 , 2021.

[36] D. Srinivasan, G. Veerappan, M. Ravichandran et al., "Investigation on electric erosion behavior of nickel-based super alloy (Waspaloy: $\mathrm{Ni}, \mathrm{Cr}, \mathrm{Co}, \mathrm{Mo}, \mathrm{Ti}, \mathrm{Al}$ ) using response surface methodology," Surface Topography: Metrology and Properties, 2021.

[37] R. Dharmaraj, A. Karthick, G. K. Arunvivek et al., "Novel approach to handling microfiber-rich dye effluent for sustainable water conservation," Advances in Civil Engineering, vol. 2021, 10 pages, 2021.

[38] U. Muthuraman, R. Shankar, V. K. Nassa et al., "Energy and economic analysis of curved, straight, and spiral flow flatplate solar water collector," International Journal of Photoenergy, vol. 2021, Article ID 5547274, 11 pages, 2021.

[39] A. M. Manokar and A. Karthick, "Review on progress in concrete solar water collectors," Environmental Science and Pollution Research, vol. 28, no. 18, pp. 22296-22309, 2021.

[40] R. Naveenkumar, M. Ravichandran, B. Stalin et al., "Comprehensive review on various parameters that influence the performance of parabolic trough collector," Environmental Science and Pollution Research, vol. 28, no. 18, pp. 2231022333, 2021. 